\title{
Review of properties of high strength concrete after high temperature
}

\author{
Dongfu Zhao ${ }^{1,2,3}$, Yuchen Liu ${ }^{2 b, *}$ \\ ${ }^{1}$ Beijing University of Civil Engineering and Architecture, Beijing 100044, China \\ ${ }^{2}$ School of Civil and Transportation Engineering, Beijing University of Civil Engineering and \\ Architecture, Beijing 100044, China \\ ${ }^{3}$ Engineering Structure and New Materials of Beijing University Engineering Research Center, \\ Beijing University of Civil Engineer and Architecture, Beijing 100044, China \\ azhaodongfu@bucea.edu.cn「liuyuchen118@126.com
}

Keywords: high strength concrete; high temperature; mechanical propertiey; durability.

\begin{abstract}
In this paper, the research results of mechanical property and durability of high-strength concrete subjected to high temperature were comprehensively reviewed, the research status of mechanical property and durability of high-strength concrete at elevated temperature were discussed, and existing problems were analysed, finally, main research directions of mechanical property and durability of high-strength concrete subjected to high temperature were forecasted.
\end{abstract}

\section{Introduction}

With the development of building technology, high-strength concrete is more and more used in all kinds of projects. Compared with ordinary concrete high strength concrete has many advantages such as high strength, low permeability and good durability. Using the high-strength concrete in the construction can not only reduce the size of the building but also improve the life of the building and reduce the costs of maintenance and repair, it can adapt to the development directions of modern engineering to large span, tall, heavy, But also to meet the needs of resisting the harsh environmental conditions $^{[1-6]}$. However, with the development of e experimental research in recent years, people gradually realize that the high strength concrete is sometimes worse than the performance of ordinary concrete. Especially after high temperature the high strength concrete had serious degradation. Due to the high density and low permeability, the mechanical properties of high strength concrete are attenuated, and often accompanied by the burst phenomenon after high temperature. This will have a greater impact on the reliability of concrete structures ${ }^{[7-10]}$. Therefore, the study of mechanical property and durability of high-strength concrete after high temperature will have great theoretical significance and practical value.

\section{Research Status of Mechanical Properties of High Strength Concrete after High Temperature}

Domestic and foreign research on high temperature mechanical properties of high-strength concrete has been more fruitful. Castillo ${ }^{[11]}$ studied the mechanical properties of high strength concrete after high temperature with preloading or not, the results showed that: no matter whether or not the pre load, with the increase of temperature, high strength concrete strength decreased, the peak strain increased. The heating temperature is $100,300^{\circ} \mathrm{C}$, the rate of strength loss were $15 \%, 20 \%$, the loss of strength increases with the increase of the concrete grade. Poon ${ }^{[12]}$ the studied the mechanical properties of different content of steel fiber concrete after high temperature by static load test, and found that steel fiber can significantly improve the residual compressive strength of high strength concrete after high temperature. When the dosage of steel fiber volume fraction is $1 \%$, The compressive strength of steel fiber high strength concrete after $600^{\circ} \mathrm{C}$ high temperature is $50 \%$ of compressive strength of high strength concrete at room temperature. When the heating temperature 
reached $800^{\circ} \mathrm{C}$, the residual compressive strength is $30 \%$ of compressive strength of high strength concrete at room temperature. After $600{ }^{\circ} \mathrm{C}$, the compressive strength of high strength concrete without steel fiber is $45 \%$ of compressive strength of high strength concrete at room temperature, and the compressive strength of high strength concrete after $800^{\circ} \mathrm{C}$ is $23 \%$ of compressive strength at room temperature. Behnood ${ }^{[13]}$ studied the mechanical properties of high temperature concrete mixed with silica fume after high temperature. The results show that When the heating temperature is $600{ }^{\circ} \mathrm{C}$ the compressive strength of high strength concrete with $6 \%$ and $10 \%$ silica fume content decrease of $6.7 \%$ and $14.1 \%$ that at room temperature. When the heating temperature is $100{ }^{\circ} \mathrm{C}$ and $200{ }^{\circ} \mathrm{C}$ the content of silica fume has no effect on the residual compressive strength of concrete.

Guo ${ }^{[14]}$ think when heated at the temperature above $600^{\circ} \mathrm{C}$, high strength concrete strength will be greatly decreased, because the $\mathrm{Ca}(\mathrm{OH}) 2 \mathrm{Ca}(\mathrm{OH}) 2$ dehydrates into free $\mathrm{CaO}$ upon heating, And if $\mathrm{CaO}$ contact with water vapor after cooling will be a chemical change to $\mathrm{Ca}(\mathrm{OH})_{2}$. In this process, the volume swell lead to the internal stress inside the concrete and make concrete damage. Li Min Qian Chunxiang et al. ${ }^{[15]}$ studied the effects of fire temperature, strength grade and specimen size on the mechanical properties of high strength concrete after high temperature. The results show that the compressive strength is affected by the heating rate obviously. When the heating rate is large the surface and internal temperature gradient of high strength concrete are obvious and the thermal stress is large which leads to the decrease of concrete strength and the degree of deterioration is larger than that of ordinary concrete. In addition the u strength of the large-size concrete block after the fire is less than the small size of the loss. Because there is a temperature field inside the concrete. The internal temperature of the specimen is lower than that of the external fire surface. Therefore the temperature inside the large size specimen is smaller than that of the small size, and resulting in less loss of strength. ZHAO Dongfu LIU Mei ${ }^{[16-17]}$ carried out uniaxial compression tests on high-strength concrete with heating temperature of $100-900{ }^{\circ} \mathrm{C}$ and constant temperature time of 0.5-3h, and given variation law of residual strength of high strength concrete with different high temperature. In addition, using SEM, X-ray XRD, mercury pressure measurement ultrasonic and microhardness testing to analyze the physical and chemical changes of the high-strength concrete after the different high temperature. The relationship between the temperature history and the microstructure evolution of high strength concrete was established. Wu Bo ${ }^{[18]}$ studied C70 and C85 two high-strength concrete mechanical properties after high temperature. The results show that the strength and elastic modulus of high strength concrete decrease gradually with the increase of temperature and the peak strain gradually increases. And through the regression analysis the corresponding regression formula is given. Song Yupu and He Zhenjun ${ }^{[19-20]}$ studied the multi-axial mechanical properties of high-strength concrete after high temperature. The results show that the biaxial compressive strength of high - strength concrete is higher than that of single - axial compressive strength in the same temperature grade. The improvement ratio depends on the stress ratio and the brittleness of concrete after high temperature.

Combining with the above research results it has been found that the research on the mechanical properties of high strength concrete after high temperature has made some progress including the residual strength deformation modulus and peak strain of high strength concrete. The fatigue properties of high strength concrete after high temperature have not been reported.

\section{Research Status of Durability of High Strength Concrete after High Temperature}

At present the research on the durability of high-strength concrete at high temperature is still in the initial stage. The research mainly focuses on the permeability of high-strength concrete after high temperature. However there is a little research on the measures to improve the durability after high temperature concrete and the durability life evaluation of high strength concrete structure after fire. Noumowe A.N et al. ${ }^{[21]}$ conducted high temperature and permeability tests on ordinary high strength concrete and $2 \mathrm{Kg}$ polypropylene fiber reinforced high strength concrete. The results show that: the two kinds of high strength concrete have obviously improved on chloride ion permeability after high 
temperature. Poon CS ${ }^{[22,23]}$ studied the permeability of HSC which mix of silica fume, blast furnace slag and volcano ash which been heated to $600^{\circ} \mathrm{C}$ and constant temperature 1hour. The results show that: the chloride ion permeability coefficient of all kinds of concrete has obvious rise. Yan $\mathrm{X}^{[24]}$ use two different heating mechanisms to heat the dolomite aggregate and pebble aggregate high strength concrete, and carried out chloride ion permeability test. The experimental results show that the heating mechanisms has a great influence on the high strength concrete of pebble aggregate but has no effect on the chloride ion permeability of dolomite aggregate high temperature concrete after high temperature. Zhang Yi,Jin Weiliang ${ }^{[25,26]}$ test the chloride ion permeability of C50 C70 high strength concrete after high temperature. The results show that the permeability of concrete is affected by temperature and the concrete with different strength grades is resistant to chloride ion after high temperature. Li Min Qian Chunxiang ${ }^{[27,28]}$ studied the permeability of basalt aggregate high strength concrete and limestone aggregate high strength concrete after high temperature by chloride ion permeability coefficient, wet migration permeability coefficient and air permeability coefficient respectively. The permeability of high strength concrete after high temperature has a more substantial increase than normal temperature. And the three coefficients can be a good response to the changes of permeability of high-strength concrete after the high temperature. And the relationship between the three coefficients is established according to the experimental data. Zhou Peng ${ }^{[29]}$ studied the effect of different thickness of the fire retardant coating to C80 concrete after high temperature. The results show that the fireproof coating can effectively reduce the chloride ion permeability of concrete after fire thus effectively improving the durability of high strength concrete.

\section{Conclusions}

This paper summarizes the research results on the mechanical properties and durability of high concrete after high temperature at home and abroad in recent years, and analyzes the present situation. Among them the current stage of high temperature concrete for high temperature research there are the following questions:

(1) At home and abroad the research on the mechanical properties of high-strength concrete after high temperature is mainly focused on the residual strength elastic modulus and stress-strain curve and the fatigue performance of high-strength concrete after high temperature has not been reported.

(2) The research on the durability of high-strength concrete after high temperature is mainly focused on the influence of high temperature on the permeability of various high-strength concrete but the relationship between high-temperature concrete permeability and residual life has not been systematically studied. At the same time the research on the measures to improve the durability of high-strength concrete after high temperature is rarely reported.

(3) For research of high-strength concrete after high temperature the selected temperature condition is not complete which is not conducive to assessment of the bearing capacity and durability of high-strength concrete structures after fire.

\section{Acknowledgments}

This work was financially supported by the National Natural Science Foundation of China (51378045).

\section{References}

[1]He Zhenjun, Song Yupu. Multiaxial tensile-compressive mechanical behaviour of plain high-strength high- performance concrete [J]. Engineering Mechanics,2010, 25(10):190-195(in Chinese)

[2] Saber Fallah, Mahdi Nematzadeh. Mechanical properties and durability of high-strength concrete containing macro-polymeric and polypropylene fibers with nano-silica and silica fume [J]. Construction and Building Materials, 2017 Vol.132 :170-187 
[3] Raju, M. Potha,Rao, K. Srinivasa,Raju, P. S. N. Compressive strength of heated high-strength concrete [J] . Magazine of Concrete Research, 2007 Vol.59 :79-85

[4] Mohamed Amina, Khaled Abu el-hassan. Effect of using different types of nano-materials on mechanical properties of high strength concrete [J]. Construction and Building Materials. 2015 ( 80):116-124

[5] Vahid Afroughsabet, Togay Ozbakkaloglu. Mechanical and durability properties of high-strength concrete containing steel and polypropylene fibers[J]. Construction and Building Materials. 2015 (94) :73-82

[6] Ayman Moustafa, Mohamed A. ElGawady. Mechanical properties of high strength concrete with scrap tire rubber [J]. Construction and Building Materials .2015 (93) 249-256

[7] Liu Xian, Yuan Yong, Ye Guang. Investigation on the mechanism of explosive spalling of high performance concrete at elevated temperatures[J]. Journal of tongji university (natural science).2008,41(6): 61 -68(in Chinese)

[8] Liu Xian , Yuan Yong, Ye Guang. Study on Pore Structure Evolution of High Performance Concrete with Elevated Temperatures [J]. China Civil Engineering Journal.2008,6(11): 1473 1478(in Chinese))

[9] Liu Mei Research on Relationships of Temperature History and Micro-structure Evolution Mechanism of High-strength Concrete [D]. Beijing University of Civil Engineering and Architecture,2016(in Chinese)

[10] Noumowe,A. Mechanical properties and microstructure of high strength concrete containing polypropylene fibers exposed to temperatures up to $200^{\circ} \mathrm{C}$ Cement and Concrete Research, 2005, 35(11), p2192-2198.

[11] Castillo C,Durrani A J. Effect of transient high temperature on high-strength concrete[J].ACI Materials Journal, 1990,87(1):47-53.

[12]Poon C S, Shui Z H, Lam L. Compressive behavior of fiber reinforced high-performance concrete subjected to elevated temperatures[J].Cement and Concrete Research, 2004, 34(12):2215-2222.

[13]BEHNOOD A, ZIARI H. Effects of silica fume addition and water to cement ratio on the properties of high-strength concrete after exposure to high temperatures[J].Cement and Concrete Composites, 2008, 30(2):106-112.

[14]Guo Zhenhai Li Wei.Experimental Study on Thermal Mechanical Properties of Concrete [M].Beijing: Tsinghua University Press,1991: 78-98.

[15]Li Min, Qian Chunxiang.Sun Wei. The varying rule and the non-destructive measuring of high Performance concrete after fire [J]. Industrial Construction,vo1.32, 10, 2002.

[16]Zhao Dongfu , Liu Mei Experimental Study on Residual strength and Nondestructive Testing of High Strength Concrete after High Temperature[J]. Journal of Building Structures, 2015, 36(2): 365 -372(in Chinese)

[17]Liu Mei Research on Relationships of Temperature History and Micro-structure Evolution Mechanism of High-strength Concrete[D]. Beijing University of Civil Engineering and Architecture,2016(in Chinese)

[18] Wu bo, Yuan jie, Wang Guangyuan. Experimental research on the mechanical properties of hsc after high temperature[J]. China Civil Engineering Journal,2000, 33 (2): 8-12(in Chinese) 
[19]He Zhenjun.Experimental Study on the Multiaxial Mechanical Behavior of Plain High-strength Concrete before and after High Temperatures[D]. Dalian University of Technology, 2002(in Chinese)

[20]He Zhenjun Song Yupu. Mechanical properties of plain high-strength high-performance concrete under biaxial compression after exposure to high temperatures[J]. Chinese Journal of Theoretical and Applied Mechanics,2008,40（3）:364-373(in Chinese)

[21] Noumowe A N, Siddique R, Debicki G. Permeability of high-performance concrete subjected to elevated temperature $\left(600^{\circ} \mathrm{C}\right)[\mathrm{J}]$. Construction and Building Materials, 2009, 23(5): 1855-1861

[22] Poon C S, Azhar S, Anson M, Wong Y L. Comparison of the strength and durability performance of normal-and high-strength pozzolanic concretes at elevated temperatures[J]. Cement and Concrete Research, 2001, 31(9): 1291-1300

[23]Poon C S, Azhar S, Anson M, Wong Y L. Performance of metakaolin concrete at elevated temperatures[J]. Cement and concrete composites, 2003, 25(1): 83-89

[24] X, Li H, Wong Y L. Assessment and repair of fire-damaged high-strength concrete: Strength and Durability[J]. Journal of Materials in Civil Engineering, 2007, 19(6): 462-469

[25]Zhang Yi. "Study on the Durability of Post-fire Concrete Structure” D. thesis, Zhejiang University,2005. (in Chinese)

[26]JIN Wei-liang, ZHANG Yi. Fire's effect on chloride ingress related durability of concrete structure[J]. Zhejiang Univ Sci A 2007 8(5):675-681.

[27]Li Min, Qian Chunxiang. Degradation of permeability resistance of high strength concrete after exposed to fire Journal of Southeast University,2006,36(5) , pp. 825-830(in Chinese)

[28] Li Min. "The fire damadge of high strength concrete and its comprehensive evaluation” Ph.D. thesis, Southeast University,2005(in Chinese)

[29]Zhou Peng. "Preliminary Study on High Strength Concrete with Fire Insulation” D. thesis, South China university of Technology,2010. (in Chinese) 